\title{
Minisymposium
}

\section{Considering intersections of race and gender in interventions that address US men's health disparities}

\author{
D.M. Griffith*, J.M. Metzl, K. Gunter \\ Center on Men's Health Disparities, Department of Health Behavior \& Health Education, School of Public Health, \\ University of Michigan, 1415 Washington Heights, SPH I, Ann Arbor, MI 48109 2029, USA
}

\section{A R T I C L E I N F O}

Article history:

Available online 2 July 2011

\section{Keywords:}

Gender

Men's health

Health disparities

Social determinants of health

Health inequalities

Men's health disparities

\begin{abstract}
S U M M A R Y
Although gender, racial and ethnic differences in health in the USA are well documented, it is less clear how race and gender intersect to produce large and consistently poor health outcomes for men of colour, particularly Black American men. This paper will illustrate how race and gender intersect at multiple levels to shape men's health and health behaviours, and function as fundamental social determinants of health. The paper will conclude by discussing the need to attend to the role of male gender in pathways and processes underlying racial health disparities, and the challenges of developing health promotion interventions for Black American men.

(c) 2011 The Royal Society for Public Health. Published by Elsevier Ltd. All rights reserved.
\end{abstract}

In the USA, current calls to promote health equity and to address health disparities highlight the need for research that examines the pathways through which health disparities are created and maintained. ${ }^{1}$ To date, much of the literature on health disparities, health equity and social determinants of health in the USA has focused on disentangling factors associated with race and ethnicity from those associated with social and economic status, class and position. ${ }^{2,3}$ Research on health disparities and social determinants of health highlights four key issues: factors that influence health over the life course, contexts that shape access to environmental resources, mechanisms that directly and indirectly influence health behaviours and health outcomes, and processes that systematically advantage some and disadvantage others. ${ }^{4-7}$

A key aspect of research on health disparities and social determinants of health is the identification of fundamental social factors that are antecedents to socio-economic class and position. ${ }^{8,9}$ Gender, particularly male gender, is a fundamental social determinant of men's health which dramatically illustrates that factors other than socio-economic status affect health. ${ }^{10}$ Socio-economic status and position contribute heavily to racial and ethnic disparities, but because men are more economically and socially advantaged in most cultures, there is no theory to explain men's social and economic power yet lower life expectancy compared with women. ${ }^{11}$

The ways in which class, gender and race relations intersect to shape women's health outcomes has received some attention, ${ }^{12}$ yet we remain challenged to understand what these intersections might mean for men. ${ }^{13}$ Over at least the past 15 years, scholars have paid increasing attention to the potentially negative health impact of gendered expectations and normative gender roles on men's health. ${ }^{14-16}$ Gender is a dynamic social structure that men and women continually convey and reconstruct in daily interactions. ${ }^{17}$ Whether a person is judged to look male or female by others evokes a constellation of gendered social expectations, responsibilities and obstacles. ${ }^{18}$

\footnotetext{
* Corresponding author.

E-mail address: derekmg@umich.edu (D.M. Griffith). 0033-3506/\$ - see front matter @ 2011 The Royal Society for Public Health. Published by Elsevier Ltd. All rights reserved. doi:10.1016/j.puhe.2011.04.014
} 
The gendered expectations that are imposed on members of each sex are shaped by race, ethnicity and other key social structures and identities. ${ }^{18}$ It is critical to examine how sex and gender intersect with other aspects of men's identities and experiences to accurately capture the experience of indigenous men, poor men and men of colour around the world. Globally, these men account for much of the reported gender difference in mortality, ${ }^{19,20}$ but their health and health care are overlooked, not prioritized and not considered an issue of focus in many countries. ${ }^{21}$

This paper will argue that it is critical to focus more research on men's health disparities, meaning research that considers how the individual- or population-level health behaviours and health outcomes of men are determined by cultural, environmental and economic factors associated with their socially defined identities and group memberships. Approaching health disparities with focused attention on men's health disparities highlights gendered pathways that increase men's risk of developing or dying from certain conditions and illnesses, and helps to identify positive aspects of masculinity by considering how men marshal social and cultural resources to mitigate racism, ethnic oppression and other forces that may adversely affect their health.

The authors are also interested in creating a research agenda on men's health disparities that examines: (1) how masculinities are related to health ${ }^{20}$; (2) how gender is constructed and embedded in social, economic and political contexts and institutions ${ }^{19}$; and (3) how culture and subcultures influence how men develop their masculinities and how they respond to health issues. Masculinity has multiple forms and resides within individuals and their social and cultural contexts. ${ }^{22,23}$ While research has illustrated the importance of considering underlying social determinants of health, including socio-economic status and race-based residential segregation, ${ }^{7,24-28}$ this paper argues that public health needs more research on men's health disparities, which explores how gender and notions of masculinity intersect with processes of racialization in shaping policies from local to global levels that affect health.

In the following text, the authors discuss key conceptual issues facing the study of masculinity, health disparities, social determinants of health and men's health using the example of Black American men. While many countries across the globe have different conceptualizations and categorizations of race and ethnicity, it is important to consider the implications of these categories for health. In this paper, the terms 'Black Americans' and 'Blacks' are used interchangeably to characterize a racial group in the USA that includes considerable ethnic heterogeneity and includes African Americans, Caribbean Blacks, Blacks from Latin America and Blacks from Africa. Black Americans are compared with White Americans who, similarly, represent a broad racial group with considerable ethnic heterogeneity. Ethnic heterogeneity and ethnicity are critical concepts to consider in efforts to eliminate health disparities, because they help to capture the unique cultural and social characteristics of groups that often represent strengths and resources to mitigate stressors from the society in which ethnic groups are situated. ${ }^{29}$ Despite the social relevance of ethnicity in the USA and globally, the authors chose to focus on race as it is defined in the USA because it tends to represent the broad structural forces that most fundamentally shape historical and current economic and social opportunities that may map on to cultural factors, social practices and institutional policies that adversely affect the health of socially defined groups in other countries.

Black American men represent a useful model for examining key concepts, mechanisms and pathways through which social determinants affect health. As manhood is fundamentally racialized and class bound, it is useful to examine how race, ethnicity and gender intersect through a population that has faced considerable structural barriers as a result of the intersection of these factors. Examining the health outcomes of Black American men helps to illustrate the importance of a group's location in a socially constructed hierarchy, in this case a racial hierarchy, which shapes life chances, access to opportunities and resources, and health outcomes. ${ }^{8,29}$

The concept of embodiment is useful in efforts to describe how daily unconscious practices, health behaviours and health outcomes are shaped by gender-specific, socially located contexts. ${ }^{11,17}$ The stigma and cultural scripts and schemas associated with race have led to Black Americans being deemed three-fifths of a person in the US Constitution, the legalization of chattel slavery in the USA, and institutionalization of racebased segregation as social, economic and housing policies for much of the 20th Century. Each of these decisions was not only adjudicated by the federal justice system, but had the support of major economic, cultural and scientific institutions. ${ }^{7,24}$ Thus, studying Black men provides a useful lens through which to look beyond explicit health and social policies that differentially benefit or harm the population, to how global, national, state and local forces give meaning to socially constructed hierarchies that influence health.

Discussion of men's health disparities will begin with a selected review of gender differences in health among Black American, middle-aged adults, followed by discussion of the unique challenges that arise in efforts to intervene to improve the eating behaviour and physical activity of Black American men. This paper will focus on health behaviours that are critical for health promotion and health maintenance for men regardless of race, ethnicity or country of residence. Eating and physical activity are closely tied to fundamental structural barriers to health and the leading causes of death for men in general and Black American men in particular. ${ }^{30-33}$ The paper will conclude by offering recommendations for addressing men's racial and ethnic health disparities more broadly.

\section{Gender and the health of Black American adults}

While researchers and policy makers call for greater focus on social determinants of racial and ethnic disparities in health, there is a critical need to recognize how specific groups of men may not benefit equally from efforts to address racial or ethnic disparities. ${ }^{10,34,35}$ Black American men and women face very different manifestations of racial barriers and patterns of the relationship between social determinants and health. For example, the inability to close the Black-White gap in mortality over the last four decades masks an important gendered story. ${ }^{36}$ The mortality gap between Black and White women, 
particularly those in their childbearing years, has closed, while the gap between Black and White men, particularly those ages ${ }^{45-64}$ has widened. Black men have not experienced the same improvements in wealth as White men or Black women. The socio-economic status of Black American men is positively related to stress, even though socio-economic status is inversely related to stress for Black American women. ${ }^{34,35}$

In the USA, masculinity is often signified by beliefs and behaviours that are practiced in social interactions; thus, masculinity varies between cultures, races, ethnicities and individuals. ${ }^{57}$ Part of the way in which gender functions, however, is to hide contradictions about how men ought to behave and what type of power and authority men should have, while appearing as though gender is a static fact of nature; gender dynamics often seem to consist of unchanging, transhistorical, naturally occurring traits. $^{58}$ Gendered processes are based on arbitrary historical and ideological processes linking male genital anatomy, male identity and social arrangements of authority and power, despite the fact that these factors have no intrinsic relationship.

Gender intersects with structural racism in complex and dynamic ways to influence the cultural schemas that shape Black American men's lives and health outcomes. For Black American men, race, ethnicity, identity and ideals of masculinity are often defined by their ethnic identity and shaped by experiences with White American society. For Black American males, notions of masculinity are viewed as symbols of economic prosperity and social standing. ${ }^{59}$ Notions of masculinity assigned and defined by mainstream White American society to Black American males are often the cause of internal conflict and painful attempts by these men to acknowledge, fulfill or reject such roles and identity. ${ }^{59}$

US cultural norms and the social and cultural beliefs of Black Americans must be considered in a gendered context. ${ }^{60}$ Black American men often embody their efforts to fulfil socially and culturally valued roles in the context of economic, educational and social barriers and challenges. Despite the changes and flexibility in gender roles over time, the family provider role continues to be a salient aspect of Black American men's identity ${ }^{60}$ Particularly during their middle-adult years, Black American men's evaluations of how well they feel they are fulfilling the roles of provider, husband, father, employee and community member are fundamental aspects of their identities. ${ }^{60,61}$ From approximately 34-60 years of age, ${ }^{62,63}$ fulfilling the provider role is the major focus. ${ }^{37,60,64}$

Black American men, when compared with White men, are less likely to be able to fulfil this important provider role. Sociologist David Williams highlights how middle class status is often recent, tenuous and marginal for many Black Americans with the following three examples ${ }^{35}$ : college-educated Black Americans are four times more likely to experience unemployment than White Americans ${ }^{38}$; middle class Black Americans have markedly lower levels of wealth compared with middle class White Americans ${ }^{39}$; and middle class Black Americans are less likely to be able to translate similar levels of education and income into desirable housing and neighbourhood conditions than middle class White Americans. ${ }^{40}$ These economic frustrations may help to explain why socioeconomic status was inversely related to suicide for White American men but positively related to suicide for Black
American men. ${ }^{35,41,42}$ Additionally, poverty and education have a significant impact on suicide rates among Black American males, with poverty reducing the risk of suicide, and educational attainment increasing the risk of suicide. ${ }^{43}$

Isaacs et al. (2008) found that among people in their 30s, both Black American women and White American women had substantially higher incomes than women in their mother's generation; on the other hand, men in their 30s, particularly Black American men, actually fared worse. The failure of a typical man in his 30s to earn as much as men in his father's generation may be particularly problematic if he is trying to fulfill a provider role for a family. This gendered economic pattern may contribute to the decline in marriage rates, high rates of divorce and high rates of single mothers among Black Americans. ${ }^{44}$ Structural interventions and policies aimed at improving the health of Black Americans should uniquely consider the particularly deleterious effects of the unique economic challenges of Black American men.

\section{Obesity, eating behaviour and physical activity among Black American men}

On average, Black American men die over 7 years earlier than women of all races, and Black men die younger than all other groups of men except Native American men. ${ }^{30,45,46}$ Black American men are also more likely than other segments of the population to have undiagnosed or poorly managed chronic conditions. ${ }^{47-49}$ Over the last decade, obesity has increased significantly among men, particularly Black American men. ${ }^{50,51}$ While the prevalence of obesity is higher in Black American women than men, $40 \%$ of Black American men aged $40-59$ years and $38 \%$ of Black American men aged $\geq 60$ years are obese. ${ }^{50,51}$ The rate of grade 3 obesity (i.e. body mass index $\geq 40$ ) is $50 \%$ higher for Black American men aged $40-59$ years compared with their White male counterparts, and the rate for Black American men aged $\geq 60$ years is twice that of their White male counterparts. ${ }^{50}$ Approximately half of Black American men in the USA report no leisure-time physical activity. ${ }^{52}$ Black American men aged 35-50 years eat, on average, only 3.5 of the nine recommended daily servings of fruits and vegetables, fewer than any other racial or ethnic group of men or women. ${ }^{53}$ Approximately one-quarter $(24.4 \%)$ of Black American men are obese, which is second only to the obesity rate for American Indian/Alaska Native men. ${ }^{52}$ These patterns of disease suggest that gender-related factors play an important role in Black American men's eating behaviour and physical activity.

\section{Challenges in developing interventions for Black American men}

When developing an intervention for Black American men, the authors sought strategies to refine understanding of where and how to intervene to improve African American men's eating behaviour and physical activity. African American men are a subgroup of Black Americans who are the first or second generation of their family born in the USA. The literature was searched for guidance on cultural sensitivity. 
Cultural sensitivity is the extent to which health promotion materials and programmes incorporate ethnic/cultural characteristics, experiences, norms, values, behaviour patterns, consumer preferences and beliefs of a focus population, as well as relevant historical, environmental and social forces in design, delivery and evaluation ${ }^{54}$ While the very notion of race-based cultural sensitivity training has come under constructive criticism from an array of scholars, ${ }^{55}$ it remains a useful heuristic for addressing matters of cultural difference in relation to discourses of health.

One useful strategy that has been used to develop culturally sensitive interventions is 'ethnic mapping'.54,56 This process has been used to provide valuable information for tailoring interventions by asking focus groups of the population of interest to classify aspects of the target behaviour along a continuum. Most often, because cultural sensitivity has been operationalized in relation to race or ethnicity, participants have been asked to rate foods or types of physical activity on a continuum of race/ethnicity (e.g. mostly a Black thing; equally a Black and White thing; mostly a White thing). This question presumes that the primary barriers to behaviour change are associated with knowledge and attitudes about food or physical activity. Two more basic questions, however, have rarely been asked: what aspects of identity (race, ethnicity, gender, sexual orientation) should be the primary focus of an intervention? How do we develop culturally sensitive messages for populations where two, or more, aspects of their identity are particularly salient to the behaviours of interest? The process of ethnic mapping provides a useful example of the difficulty faced when applying these strategies to African American men. As the authors did not develop an intervention that disentangles race and ethnicity among Black Americans, this paper will focus on the lessons learnt from working with African American men.

Ethnic mapping implicitly assumes that race and ethnicity are synonymous, and that race/ethnicity is the most salient aspect of identity that is relevant to behaviour change. The epidemiological data, however, suggest that male gender is an equally important aspect of identity that may influence health behaviour. Based on this premise, how do we adapt the mapping process for use with African American men? Do we first ask men to rate items or activities along an ethnic continuum, and then ask them to do the same along a gender continuum (e.g. mostly a male thing; equally a male and female thing; mostly a female thing)? Do we challenge men further by inviting them to rate items in a more complex, $2 \times 2$ matrix, may be crossing ethnicity and gender (e.g. mostly an African American male thing; mostly a White female thing; equally an African American male or an African American female thing)? The authors found that neither solution was satisfactory, and needed to rethink the fundamental relationship between African American men's identity and their health behaviour by considering how their ethnic and gender identities intersect.

\section{Beyond cultural sensitivity: the importance of an intersectional approach to interventions}

Critical masculinity scholars have emphasized the importance of locating men's health in the context of class-based, racialized masculinities. ${ }^{13,19,65,66}$ Ethnicity, economic status, educational attainment and social context are all important factors that influence the type of masculinity that men construct, with implications for the differential health risk among different types of men. ${ }^{20}$ Men construct a variety of masculinities, with men from diverse cultural backgrounds also differing in their masculinity ideology. ${ }^{67}$ Relational perspectives offer different ways of being a man, rather than limiting particular forms of masculinity or hegemonic masculinity. ${ }^{68}$

Intersectional approaches suggest that it is critical to consider how individual agency and choice, contextual and environmental influences, and physiological and biological factors combine to influence health. ${ }^{12}$ In addition, an intersectional approach offers a conceptual framework through which researchers can simultaneously consider the relationship between key structural factors and aspects of identity that affect health and health behaviour. ${ }^{12,69-73}$ More fundamentally, intersectional approaches seek to help researchers become more deliberate, thoughtful and explicit about why they choose particular variables, characteristics, identities and intersections for inclusion in studies. ${ }^{74}$ When decisions about these study questions are not carefully considered, intersectional invisibility ${ }^{75}$ can occur, rendering some identities invisible. ${ }^{74}$ Ironically, in the study of racial and ethnic disparities in obesity, male gender has often been rendered invisible. Despite the need to reduce obesity in men, for example, the majority of studies on the treatment and prevention of obesity include samples that were predominantly female, ${ }^{51}$ and studies that have been considered representative of and applicable to all Black Americans regardless of sex include less than $30 \%$ men; some of the studies include samples of men as small as $10 \%{ }^{76}$

\section{Conclusions}

The goal of this paper was to highlight the importance of considering male gender in research on health disparities, social determinants of health and health equity. In research on men's health, there is a need to examine three key factors associated with male gender: how masculinities are related to health ${ }^{20}$; how gender is constructed and embedded in social, economic and political contexts and institutions ${ }^{19}$; and how culture and subcultures influence how men develop their masculinities and how they respond to health issues. ${ }^{77}$ The health needs of Black American men and other groups of men need to be explored in the contexts of their specific life circumstances and vulnerabilities, and these contexts have racial, ethnic, social, economic, gender and other components. Studying men of colour provides a useful way to examine key social, economic and cultural factors that shape men's health. ${ }^{13}$

The fact that Black American men in the USA are more likely to live in poverty, work in low-paying and dangerous occupations, reside in closer proximity to polluted environments, be exposed to toxic substances, experience threats and realities of crime, and live with cumulative worries about meeting basic needs highlights the importance of considering both gendered and non-gendered aspects of their environments, identities and experiences. ${ }^{78}$ Understanding the poor 
status of men's health and premature death includes looking at multiple social determinants of health that intersect with gender, including poverty, poor educational opportunities, underemployment and unemployment, incarceration, and social and racial discrimination. All of these factors challenge and influence the capacity of poor men and men of colour to achieve and maintain good health. ${ }^{21}$

Public health professionals must address gender as a fundamental social determinant of racial and ethnic disparities in health, and intentionally and carefully consider gender in public health interventions. While we have become more sophisticated and precise in our ability to examine some social determinants of health, including socio-economic status and race-based residential segregation, ${ }^{7,24-28}$ more attention needs to be paid to the role that male gender plays in processes of racialization in shaping regional, neighbourhood and health policies. Considering these factors will help researchers become more conscious of why they are including demographic, environmental and structural factors in their studies, and the mechanisms and pathways that underlie health disparities. Health-related policies occur in the context of race- and genderconscious ideologies that, in turn, shape the beliefs and values of policy makers, researchers and practitioners. Considering gender in behavioural, community and policy interventions will further the goal of men's health policy, which is not to reduce the health gap between men and women but to ensure that both have equal opportunities to maximize their health chances. ${ }^{15,79}$

\section{Ethical approval}

Not required.

\section{Funding}

This manuscript was supported in part by grants from the American Cancer Society (MRSGT-07-167-01-CPPB), the Michigan Center for Urban African American Aging Research (5P30 AG015281), the Cancer Research Fund of the University of Michigan Comprehensive Cancer Center, and by the Center on Men's Health Disparities, University of Michigan, School of Public Health. Its contents are solely the responsibility of the authors and do not necessarily represent the views of the funders or the University of Michigan.

\section{Competing interests}

None declared.

\section{REFERENCES}

1. Adler N. Overview of health disparities. In: Thomson GE, Mitchell F, Williams MB, editors. Examining the health disparities research plan of the National institutes of health: unfinished business. The National Academies Press; 2006. p. 121-74. Washington, D.C.

2. Kawachi I, Daniels N, Robinson DE. Health disparities by race and class: why both matter. Health Aff 2005;24:343-52.

3. Braveman PA, Cubbin C, Egerter S, Williams DR, Pamuk E. Socioeconomic disparities in health in the United States: what the patterns tell us. Am J Public Health 2010;100(Suppl. 1): S186-96.

4. Geronimus AT, Thompson JP. To denigrate, ignore, or disrupt: racial inequality in health and impact of a policy-induced breakdown of Black American communities. DuBois Reu Soc Sci Res Race 2004;1:247-79.

5. Williams DR. Race and health: basic questions, emerging directions. Ann Epidemiol 1997;7:322-33.

6. Williams DR. Race, socioeconomic status, and health. The added effects of racism and discrimination. Ann NY Acad Sci 1999;896:173-88.

7. Williams DR, Collins C. Reparations: a viable strategy to address the enigma of African American health. Am Behav Sci 2004;47:977-1000.

8. Griffith DM, Johnson J, Ellis K, Schulz A. Cultural context and a critical approach to eliminating health disparities. Ethnic Dis 2010;20:71-6.

9. Link BG, Phelan J. Social conditions as fundamental causes of disease. J Health Soc Behav 1995;35:80-94.

10. Braboy Jackson P, Williams DR. The intersection of race, gender and SES: health paradoxes. In: Schulz AJ, Mullings L, editors. Gender, race, class and health: intersectional approaches. San Francisco: Jossey-Bass; 2006. p. 131-62.

11. Lohan M. How might we understand men's health better? Integrating explanations from critical studies on men and inequalities in health. Soc Sci Med 2007;65:493-504.

12. Mullings L, Schulz AJ. Intersectionality and health: an introduction. In: Schulz AJ, Mullings L, editors. Gender, race, class and health: intersectional approaches. San Francisco: JosseyBass; 2006.

13. Pease $B$. Racialised masculinities and the health of immigrant and refugee men. In: Broom A, Tovey P, editors. Men's health: body, identity \& social context. Chichester: John Wiley and Sons; 2009. p. 182-201.

14. Broom A, Tovey P. Introduction: men's health in context. In: Broom A, Tovey P, editors. Men's health: body, identity \& social context. Chichester: John Wiley and Sons; 2009. p. 1-5.

15. Robertson S. Understanding men and health: masculinities, identity, and well-being. Maidenhead: Open University Press; 2007.

16. Connell RW. Masculinities. Oxford: Polity; 1995.

17. Robertson S. 'I've been like a coiled spring this last week': embodied masculinity and health. Sociol Health Illn 2006;28: 433-56.

18. Snow RC. Sex, gender, and vulnerability. Glob Public Health 2008;3(Suppl. 1):58-74.

19. Courtenay W. A global perspective on the field of men's health: an editorial. Int J Men's Health 2002;1:1.

20. Courtenay WH. Constructions of masculinity and their influence on men's well-being: a theory of gender and health. Soc Sci Med 2000;50:1385-401.

21. Treadwell H, Braithwaite K. Men's health: a myth or a possibility? J Men's Health Gend 2005;2:382-6.

22. Courtenay WH. College men's health: an overview and a call to action. J Am Coll Health 1998;46:279-90.

23. Smiler A. Thirty years after the discovery of gender: psychological concepts and measures of masculinity. Sex Roles 2004;50:15-26.

24. Griffith DM, Neighbors HW, Johnson J. Using national data sets to improve the health of Black Americans: challenges and opportunities. Cultur Divers Ethnic Minor Psychol 2009;15:86-95.

25. Marmot M. Action on health disparities in the United States: commission on social determinants of health. J Am Med Assoc 2009;301:1169-71.

26. Massey DS, Denton NA. American apartheid: segregation and the making of the underclass. Cambridge, MA: Harvard University Press; 1988.

27. Williams DR, Jackson PB. Social sources of racial disparities in health. Health Aff 2005;24:325-34. 
28. Williams DR, Collins C. Racial residential segregation: a fundamental cause of racial disparities in health. Public Health Rep 2001;116:404-16.

29. Ford CL, Harawa NT. A new conceptualization of ethnicity for social epidemiologic and health equity research. Soc Sci Med 2010;71:251-8.

30. Gadson SL. The third world health status of black American males. J Natl Med Assoc 2006;98:488-91.

31. Griffith DM, Johnson JL. Implications of racism for Black American men's cancer risk, morbidity and mortality. In: Treadwell HM, Xanthos C, Holden KB, Braithwaite RL (eds). Social determinants of health among African American Men. San Francisco, CA: Jossey Bass, under review.

32. Griffith DM, Allen JO, Gunter K. Social and cultural factors influence African American men's medical help seeking. Res Soc Work Pract 2011;21:337-47.

33. Griffith DM, Gunter K, Allen JO. Male gender role strain as a barrier to African American men's physical activity. Health Educ Behav, in press.

34. Watkins DC, Walker RL, Griffith DM. A meta-study of Black male mental health and well-being. J Black Psychol 2010;36: 303-30.

35. Williams DR. The health of men: structured inequalities and opportunities. Am J Public Health 2003;93:724-31.

36. Satcher D, Fryer Jr GE, McCann J, Troutman A, Woolf SH, Rust G. What if we were equal? A comparison of the black-white mortality gap in 1960 and 2000. Health Aff 2005;24:459-64.

37. Cazenave NA. Black men in America: the quest for manhood. In: McAdoo HP, editor. Black families. Beverly Hills, CA: Sage; 1981. p. 176-85.

38. Wilhem SM. Economic demise of blacks in America: a prelude to genocide? J Black Stud 1987;17:201-54.

39. Davern ME, Fisher PJ. Household net worth and asset ownership. Washington, DC: US Census Bureau; 1995.

40. Alba RD, Logan JR, Stuts BJ. How segregated are middle-class African Americans? Soc Probl 2000;47:543-58.

41. Stack S. Education and risk of suicide: an analysis of African Americans. Sociol Focus 1998;31:295-302.

42. Fernquist RM. Education, race/ethnicity, age, sex, and suicide: individual-level data in the United States, 1991-1994. Curr Res Soc Psychol 2001;6:277-90.

43. Fernquist RM. Educational attainment and the payoff of education: black male suicide in the United States, 1947-1998. Curr Res Soc Psychol 2004;9:184-92.

44. Isaacs J, Sawhill I, Haskins R. Getting Ahead or Losing Gground: economic mobility in America. Washington, DC: The Brookings Institution; 2008.

45. Kung HC, Hoyert DL, Xu J, Murphy SL. Deaths: final data for 2005. Natl Vital Stat Rep 2008;56(10):1-120.

46. Heron M, Hoyert D, Murphy S, Xu J, Kochanek K, TejadaVera B. Deaths: final data for 2006. Natl Vital Stat Rep 2009;57: $1-134$.

47. Warner DF, Hayward MD. Early-life origins of the race gap in men's mortality. J Health Soc Behav 2006;47:209-26.

48. Barnett E, Halverson J. Local increases in coronary heart disease mortality among blacks and whites in the United States, 1985-1995. Am J Public Health 2001;91:1499.

49. Harris MI, Eastman RC, Cowie CC, Flegal KM, Eberhardt MS. Racial and ethnic differences in glycemic control of adults with type 2 diabetes. Diabetes Care 1999;22:403-8.

50. Flegal KM, Carroll MD, Ogden CL, Curtin LR. Prevalence and trends in obesity among US adults, 1999-2008. J Am Med Assoc 2010;303:235-41.

51. Kumanyika SK, Obarzanek E, Stettler N, Bell R, Field AE, Fortmann SP, et al. Population-based prevention of obesity: the need for comprehensive promotion of healthful eating, physical activity, and energy balance: a scientific statement from American Heart Association Council on epidemiology and prevention, Interdisciplinary Committee for Prevention (formerly the expert panel on population and prevention science). Circulation 2008;118:428-64.

52. Ward E, Jemal A, Cokkinides V, Singh GK, Cardinez C, Ghafoor A, et al. Cancer disparities by race/ethnicity and socioeconomic status. CA-Cancer J Clin 2004;54:78.

53. National Cancer Institute (NCI). How diet affects African American men's health. 5 a Day for Better Health Program, September; 2002.

54. Resnicow K, Baranowski T, Ahluwalia JS, Braithwaite RL. Cultural sensitivity in public health: defined and demystified. Ethn Dis 1999;9:10-21.

55. Metzl JM. The protest psychosis: how schizophrenia became a Black disease. Boston: Beacon Press; 2010.

56. Resnicow K, Soler R, Braithwaite RL, Ahluwalia JS, Butler J. Cultural sensitivity in substance use prevention. J Community Psychol 2000;28:271-90.

57. Moynihan C. Theories in health care and research: theories of masculinity. BMJ 1998;317:1072-5.

58. Bederman G. Manliness and civilization: a cultural history of gender and race in the United States, 1880-1917. Chicago, IL: University of Chicago Press; 1996.

59. Hooks B. Representations of whiteness in the black imagination. black looks: race and representation. London: Turnaround; 1992. 165-178.

60. Bowman PJ. Research perspectives on Black men: role strain and adaptation across the adult life cycle. In: Jones RL, editor. Black adult development and aging. Berkeley, CA: Cobb \& Henry Publishers; 1989. p. 117-50.

61. Hammond WP, Mattis JS. Being a man about it: manhood meaning among African American men. Psychol Men Masculin 2005;6:114-26.

62. Newman BM, Newman PR. Middle adulthood. In: Newman BM, Newman PR, editors. Development through life: a psychosocial approach. 9th ed. Belmont, CA: Wadsworth Centgage Publishing; 2009. p. 452-91.

63. Erickson EH. Identity and the life cycle. New York: Norton; 1980.

64. Cazenave NA. Middle-income Black fathers: an analysis of the provider role. Fam Coord 1979;28:583-93.

65. Schofield T, Connell R, Walker L, Wood J, Butland D. Understanding men's health and illness: a gender-relations approach to policy, research, and practice. J Am Coll Health 2000;486:247-56.

66. Riska E. Masculinity and men's health: coronary heart disease in medical public discourse. Oxford: Rowman and Littlefield; 2006.

67. Wade JC. Masculinity ideology, male reference group identity dependence, and African American men's health-related attitudes and behaviors. Psychol Men Masculin 2008;9:5-16.

68. Hearn J. The problems boys and men create, the problems boys and men experience. In: Shefer T, Ratele K, Strebel A, Shabalala N, Buikema R, editors. From boys to men: social constructions of masculinity in contemporary society. Lansdowne: UCT Press; 2007. p. 13-32.

69. Bowleg L. When Black + lesbian + woman $\neq$ Black lesbian woman: the methodological challenges of qualitative and quantitative intersectionality research. Sex Roles 2008;59: 312-25.

70. Geiger HJ. What do we know? What do we need to know? What should we do? In: Schulz A, Mullings L, editors. Gender, race, class and health: intersectional approaches. San Francisco, CA: Jossey-Bass; 2006.

71. Weber L, Parra-Medina D. Intersectionality and women's health: charting a path to eliminating health disparities. In: Demos V, Segal MT, editors. Advances in gender research: gender perspectives on health and medicine. Amsterdam: Elsevier; 2003. p. 181-230.

72. Zambrana RE, Dill BT. Disparities in Latina health: an intersectional analyses. In: Schultz A, Mullings L, editors. 
Race, class, gender and health: intersectional approaches. San Francisco: Jossey-Bass; 2006. p. 192-227.

73. Weber L. Reconstructing the landscape of health disparities research: promoting dialogue and collaboration between feminist intersectional and biomedical paradigms. In: Schulz A, Mullings L, editors. Gender, race, class and health: intersectional approaches. San Francisco: Jossey-Bass; 2006. p. 21-59.

74. Warner L. A best practices guide to intersectional approaches in psychological research. Sex Roles 2008;59:454-63.

75. Purdie-Vaughns V, Eibach RP. Intersectional invisibility: the distinctive advantages and disadvantages of multiple subordinate-group identities. Sex Roles 2008;59:377-91.
76. Whitt-Glover MC, Kumanyika SK. Systematic review of interventions to increase physical activity and physical fitness in African-Americans. Am J Health Promot 2009;23: S33-56.

77. Luck M, Bamford M, Williamson P. Men's health: perspectives, diversity and paradox. Oxford: Blackwell; 2000.

78. Sabo D. The study of masculiniteis and men's health: an overview. In: Kimmel M, Hearn J, Connell RW, editors. Handbook of studies on men and masculinities. Thousand Oaks: Sage Publications; 2005. p. 326-52.

79. Doyal L. Sex, gender, and health: the need for a new approach. BMJ (Clin Res Ed.) 2001;323:1061-3. 